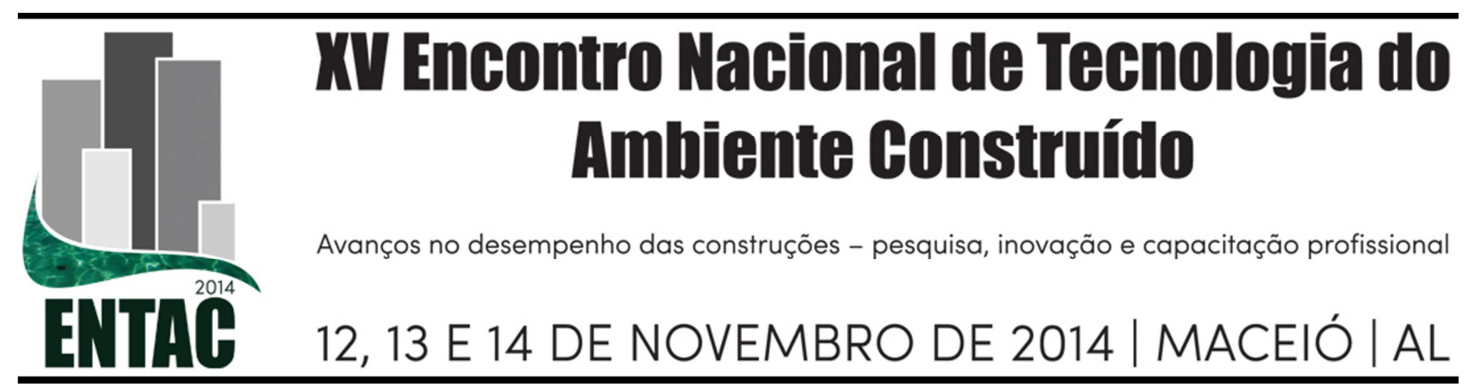

\title{
ANÁLISE DA QUALIDADE DE ESPAÇOS ABERTOS: ESTUDO DE CASO EM UM CONDOMÍNIO RESIDENCIAL
}

\section{LIMA, Erondina (1); DE MUSIS, Carlo (2); NOGUEIRA, Marta (3); FRANCO, Fernanda (4); PINTO JUNIOR, Osvaldo (5); SANTOS, Flavia (6)}

(1) UNIC Universidade de Cuiabá, (65) 92032755, e-mail: erondinaazevedo@gmail.com (2) UNIC Universidade de Cuiabá, e-mail: carlo.demusis@gmail.com, (3) UFMT Universidade Federal de Mato Grosso, e-mail: mcjanp@gmail.com, (4) IFMT - Instituto Federal de Educação, Ciência e Educação de Mato Grosso, e-mail: fermifran@yahoo.com.br, (5) UFMT Universidade Federal de Mato Grosso, e-mail: osvaldo.borges@gmail.com, (6) UFMT Universidade Federal de Mato Grosso, e-mail:

flavia_mms@hotmail.com

\begin{abstract}
RESUMO
As cidades dos países em desenvolvimento, particularmente no Brasil, têm crescido quase sem nenhum planejamento urbano, superando a capacidade dos governos em prover adequada infra-estrutura. Em cidades tropicais, a mudança climática local pode levar a uma condição que afeta a saúde humana, danifica os edifícios e aumenta o consumo de energia para a climatização artificial, sem, solucionar o problema do conforto ambiental como um todo. Segundo classificação apresentada pelo Instituto Brasileiro de Geografia e Estatística (IBGE), o clima em Cuiabá é do tipo tropical continental com estação quente-úmida e quente-seca, apresentando temperatura média anual de $27^{\circ} \mathrm{C}$. $\mathrm{O}$ objetivo do presente trabalho foi analisar duas variáveis do clima, temperatura do ar e da umidade relativa em um condomínio residencial localizado na região oeste na cidade de Cuiabá-MT. A metodologia adotada foi a do Transecto móvel, definindo-se um trajeto de 10 pontos no interior do condomínio, com uma distância aproximada de 80 metros entre eles. Os equipamentos utilizados para a coleta de dados foram Termohigrômetro e GPS. A coleta de dados realizou-se no dia 14 de setembro de 2013, em quatro horários distintos $(6 \mathrm{~h}, 12 \mathrm{~h}, 18 \mathrm{~h}$ e $24 \mathrm{~h})$. Os resultados da análise de dados mostra que a umidade relativa e a temperatura do ar variam de acordo com a configuração dos pontos estudados. Em locais com a presença de concreto, asfalto, e automóveis as temperaturas são mais elevadas e umidades relativas mais baixas, no entanto as temperaturas eram mais amenas nos pontos situados mais próximos as áreas arborizadas e gramadas. A diferença encontrada entre o ponto de maior e menor temperatura do ar foi de $1,5^{\circ} \mathrm{C}$. Sendo assim é importante salientar que há uma necessidade de implantação de áreas ajardinadas em ambientes como condomínios, praças, e espaços urbanos, pensando na melhoria da qualidade climática desses locais.
\end{abstract}

Palavras-chave: Conforto Ambiental, Cuiabá, Clima Urbano.

\begin{abstract}
The cities of developing countries, particularly Brazil, have grown almost no urban planning, exceeding the capacity of governments to provide adequate infrastructure. In tropical cities, the local climate change can lead to a condition which affects human health, damaging buildings and increases energy consumption for artificial air conditioning, without solving the problem of environmental comfort as a whole. According to the classification presented by the Brazilian Institute of Geography and Statistics (IBGE), the climate in Cuiabá is the tropical continental type with hot-humid and hot-dry season, with an average annual temperature of $27^{\circ} \mathrm{C}$. The objective of this study was to analyze two climate variables, air temperature and relative humidity in a residential condominium located in the western region in the city of Cuiabá. The methodology adopted was the mobile Transect, defining a path of 10 points inside the condo, with an approximate distance of 80 meters between them. The equipment used for data collection
\end{abstract}


were Thermohigrometer and GPS. Data collection took place on September 14, 2013, at four different times (6a.m., 12a.m., 6p.m. and 12p.m.). The results of the analysis of data shows that the relative humidity and air temperature will vary depending on the configuration of the analyzed points. In locations with the presence of concrete, asphalt, and automobiles are higher temperatures and lower relative humidities, however the temperatures were milder in points located closest wooded and grassy areas. The difference between the highest and lowest point of the air temperature was $1.5^{\circ} \mathrm{C}$. Therefore it is important to point out that there is a need to implement landscaped areas in environments such as condominiums, parks, and urban spaces, thinking on improving the quality of local climate.

Keywords: Comfort, Cuiabá, Urban Climate.

\section{INTRODUÇÃO}

Enfrentando as mudanças climáticas e o aquecimento global, os espaços ao ar livre devem ser considerados de grande importância para os planejadores e formuladores de políticas públicas, pois a melhoria da qualidade desses espaços pode contribuir muito para o conforto térmico do cidadão e gerar melhor qualidade de vida urbana. Assim, as informações climáticas devem ser avaliadas de forma sistemática e estrategicamente aplicada no processo de planejamento, (REN et. al, 2012).

As cidades ocupam $2 \%$ da superfície da Terra, mas seus habitantes consomem $75 \%$ dos recursos naturais do mundo. Sob certas condições, o calor da radiação solar e diferentes atividades urbanas podem causar o aumento da tempera do ar em certas zonas urbanas, apenas por causa da maneira em que uma cidade é estruturada, (GAGO et. al, 2013).

Preocupações com os padrões construtivos assim como seus respectivos entornos não são levados em consideração no momento da concepção urbana, gerando assim inúmeros problemas. A cidade de Cuiabá, capital do Mato Grosso, antigamente conhecida como cidade verde, vem com o passar do tempo perdendo uma parcela considerável da vegetação e área permeável que antes possuía.

Segundo classificação apresentada pelo Instituto Brasileiro de Geografia e Estatística (IBGE), o clima em Cuiabá é do tipo tropical continental de estação quente-úmida e quente-seca, apresentando temperatura média anual de $27^{\circ} \mathrm{C}$. Clima quente, o que faz com que as pessoas estão sempre em busca de abrigo do sol e evitem os locais abertos.

Tanto em ambientes públicos como em particulares os espaços ao ar livre, nota-se no comportamento das pessoas a busca pela sombra das árvores, marquises e coberturas que possam proteger da exposição solar direta.

Um importante instrumento para a regulação do clima urbano, principalmente no controle da poluição atmosférica, na amenização da temperatura, no aumento da umidade, são as áreas verdes urbanas que proporcionam uma melhoria da qualidade de vida das pessoas, (SOUCH \& GRIMMOND, 2006; SHASHUA-BAR et al., 2012).

Ao estipular os benefícios de seu processo de evapotranspiração e características morfológicas, árvores isoladas ou se plantada em grupo sempre são o melhor mecanismo de resfriamento urbano. Como moderador climático, o uso da vegetação pode contribuir criando efeito de sombra, redução da temperatura do solo e do ar, redução da infiltração solar, efeito de ventilação e minimizar o brilho da reflexão, (SHASHUA-BAR et al. 2009; WIRDOYO, 2008).

Sendo assim o estudo do comportamento climático é de grande importância para o entendimento do funcionamento das variáveis ambientais no contexto urbano. A seguinte pesquisa foi realizada na cidade de Cuiabá-MT, na área externa de um 
condomínio fechado, denominado Minas de Cuiabá. O objetivo do presente trabalho foi analisar duas variáveis do clima, temperatura do ar e da umidade relativa e a influência que o entorno de cada ponto estudado pode exercer nessas variáveis.

\section{2 ÁREA DE ESTUDO}

O local de estudo corresponde ao condomínio Minas de Cuiabá com altitude media de $175 \mathrm{~m}$, localizado entre a longitude: $56^{\circ} 7^{\prime} 3^{\prime \prime} \mathrm{W}$ latitude: $15^{\circ} 37^{\prime} 8^{\prime}$ ' S, localizado na cidade de Cuiabá capital do Mato Grosso.

Nota-se que o condomínio Minas de Cuiabá apresenta um ambiente heterogêneo, com diferentes padrões de uso e ocupação do solo, dentre os quais se destacam a área de lazer (bar, restaurante e campo de futebol) que são utilizados pelos condôminos e visitantes para o descanso, alimentação e a pratica de esportes. A área de lazer é vasta possuindo um campo de futebol que apresenta uma vegetação rasteira (grama), uma quadra de areia e vários quiosques, (Figura 1).

\section{Figura 01: (A) Imagem da área delimitada do condomínio e (B) foto de um dos}

\section{blocos de apartamentos.}
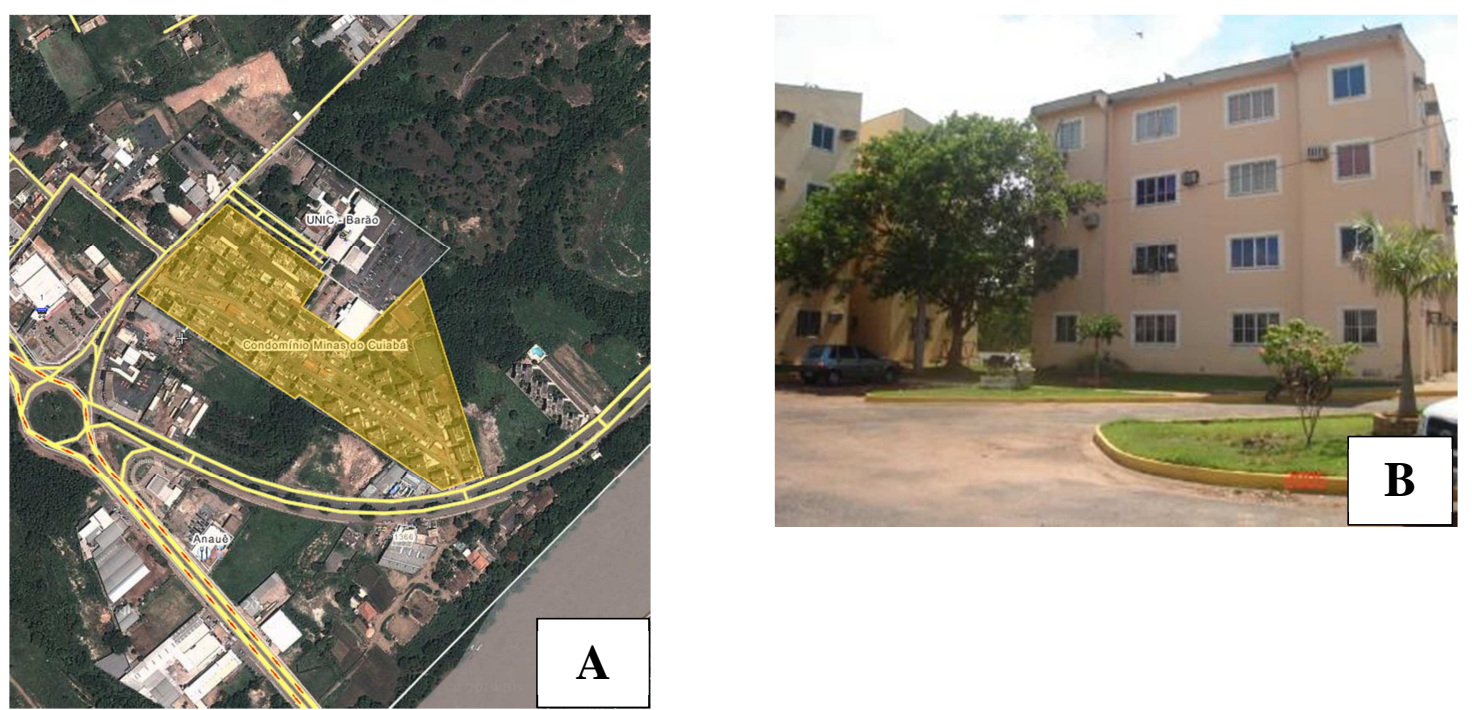

Fonte: (A) Google Earth (Setembro 2013) (B) http://www.odocumento.com.br/materia.php?id=406613

O condomínio possui trinta e dois blocos sendo que todos possuem três andares contendo quatro apartamentos, cada apartamento tem a área de aproximada $80 \mathrm{~m}^{2}$.

\section{MATERIAIS E MÉTODOS}

\subsection{Metodologia da coleta de dados}

A coleta de dado foi realizada dia 14 de Setembro de 2013, esse período do ano é considerado quente-seco. De acordo com a caracterização microclimática realizada por Campelo Jr. et al. (1991) em Cuiabá, as temperaturas médias mais elevadas foram verificadas em outubro e novembro devido à ação da Massa Tropical Continental.

As medições aconteceram em 4 horários distintos ás $6 \mathrm{~h}, 12 \mathrm{~h}, 18 \mathrm{~h}$ e $24 \mathrm{~h}$, os mesmos foram determinados pois contemplam períodos diferentes do dia, as 6h horas o sol está começando a aquecer a superfície urbana, ás 12 horas é o ápice da radiação solas, ás 18 
horas o sol está começando a se por e as 24 horas a superfície já está livre da influência da insolação. Sendo assim a os horários de medição contemplam vários aspectos do clima urbano.

Para a coleta dos dados de temperatura do ar e umidade relativa, foram demarcados 10 pontos (Figura 02), traçando assim um percurso, cada ponto com distância de $88,9 \mathrm{~m}$ entre um e outro, essa técnica é utilizada para estudar grandes áreas, denominada como transecto móvel. A técnica do transecto móvel é muito utilizada pelos estudiosos de clima urbano, em Cuiabá estudos realizados por Cox (2008), Campos Neto (2007), Barros (2012) utilizaram essa metodologia. O método do transecto móvel permite avaliar melhor a tendência térmica e higrométrica em um espaço maior dentro do contexto urbano.

\section{Figura 02: Área delimitada para o estudo.}

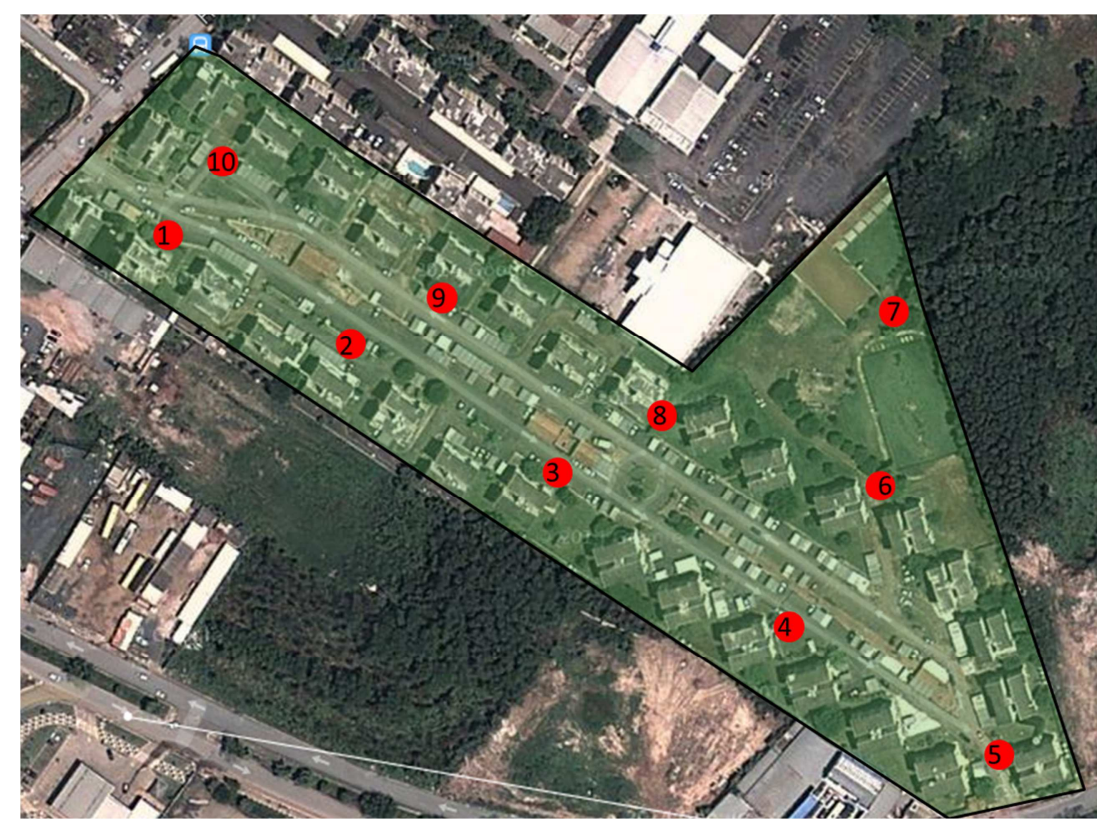

Fonte: Google Earth 09/09/2013.

$\mathrm{Na}$ escolha dos dez pontos de medida, procurou-se por pontos que se diferenciavam, principalmente, em relação a tipologia de uso e ocupação do solo.

Verifica- se os diferentes uso do solo nos pontos de coletas, Quadro 01. Os pontos 1, 3, 6 e 9 (estão posicionados em locais de sombra embaixo da copa das árvores), os pontos 2, 4, 5 e 8 (estão na sombra da garagem/telhado de zinco), o ponto 7 (tem a área com maior quantidade de árvores e vegetações) e o ponto 10 (estava á sombra no meio de 2 prédios um próximo ao outro com solo gramado). 
Quadro 01 - Denominação dos pontos e seus atributos morfológicos.

\begin{tabular}{|c|c|c|c|c|}
\hline PONTO & LONGITUDE & LATITUDE & ALTITUDE & ATRIBUTOS MORFOLÓGICOS \\
\hline 1 & 56.119 .154 & $15.618 .764,00$ & 172 & Área construída e árvores \\
\hline 2 & 56.118 .588 & $15.619 .028,00$ & 172 & Garagem com telha de zinco \\
\hline 3 & 56.118 .223 & $15.619 .253,00$ & 173 & Área construída e árvores \\
\hline 4 & 56.117 .467 & $15.619 .746,00$ & 173 & Garagem com telha de zinco \\
\hline 5 & 56.116 .185 & $15.620 .598,00$ & 172 & Garagem com telha de zinco \\
\hline 6 & 56.116 .587 & $15.619 .583,00$ & 170 & Área construída e árvores \\
\hline 7 & 56.116 .448 & 15.618 .981 & 168 & Vegetação predominante arbórea \\
\hline 8 & 56.117 .470 & 15.619 .418 & 172 & Garagem com telha de zinco \\
\hline 9 & 56.118 .100 & 15.618 .997 & 172 & Área construída e árvores \\
\hline 10 & 56.118 .993 & 15.618 .408 & 172 & Área construída e árvores \\
\hline
\end{tabular}

\subsection{Instrumentação utilizada na coleta de dados}

Foram utilizados dois equipamentos, para a coleta de dados o GPS /MAP da marca Garmin (Figura 03), modelo $76 \mathrm{Cx}$, obtendo-se as coordenadas geográficas angular e UTM ( Universal Transversa de Mercator), para precisão dos locais de medições dos pontos. Os instrumentos foram sincronizados, para que cada dado de temperatura e umidade obtivesse a coordenada do ponto.

Para a coleta das variáveis, umidade relativa $(\%)$ e temperatura do ar $\left({ }^{\circ} \mathrm{C}\right)$ no transecto foi utilizado o Termo-higrômetro digital portátil, Modelo HT - 260 da marca Instrutherm, com temperatura de operação de -20 á $60^{\circ} \mathrm{C}$, umidade relativa de 0 a $100 \%$ (Figura 03).

\section{Figura 03: (A) GPS e (B) Termo-higrômetro.}
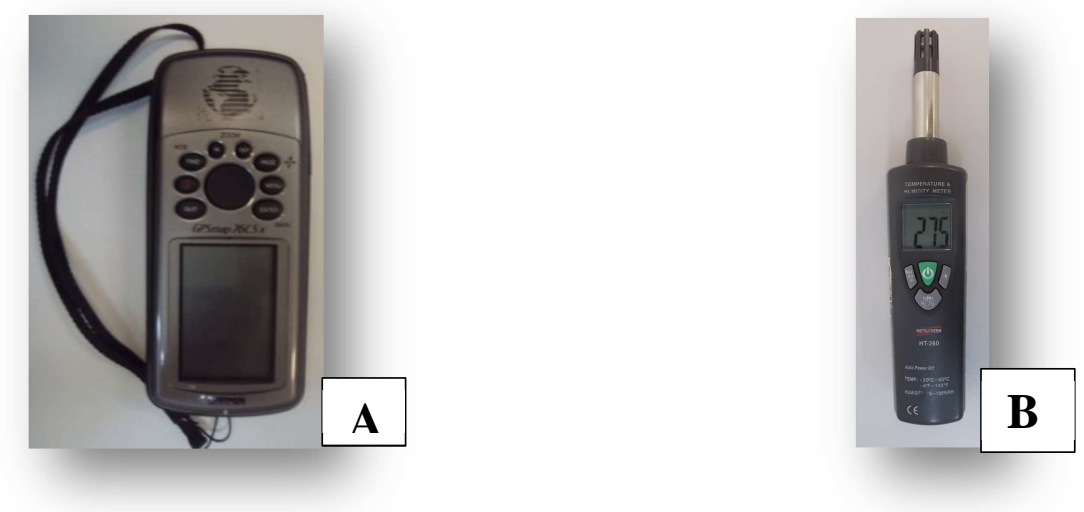

Todos os equipamentos usados na pesquisa passaram por um processo de calibração, assim também como troca de pilhas e baterias para não ocorrer possíveis imprevistos durante a coleta de dados. 
Com o intuito de verificar a variação de temperatura e de umidade relativa do ar, após as coletas foi elaborado um gráfico com os resultados, horários e informações de todos os pontos e os horários.

\section{RESULTADOS E DISCUSSÓES}

Por meio da análise das variáveis ambientais (temperatura do ar e umidade relativa) aferidas durante o estudo foi possível verificar o comportamento climático de cada ponto estudando, entendendo assim qual a influência que cada superfície tem na modificação do microclima.

Figura 04 - Gráfico da temperatura do ar nos pontos do transecto.

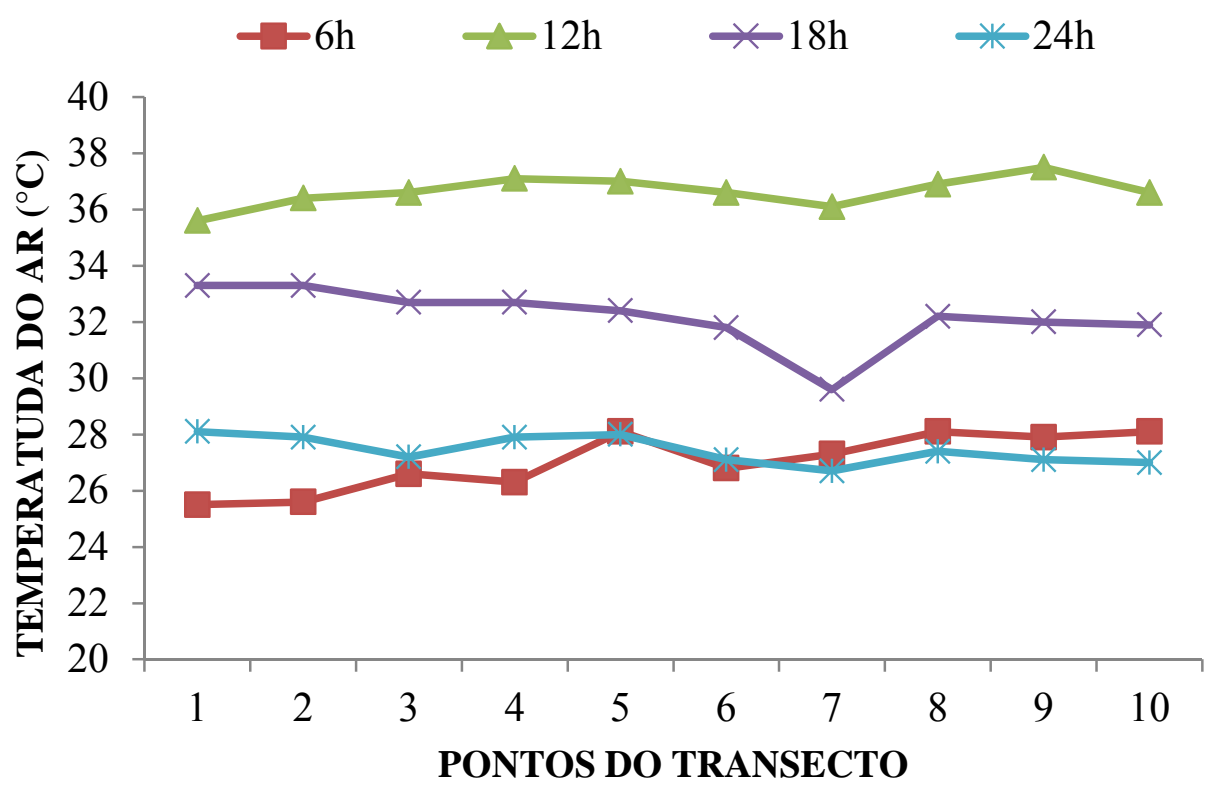

O gráfico da temperatura do ar ilustra o comportamento climático diário, onde a maior temperatura ocorre no horário das $12 \mathrm{~h}$ alcançando uma média $36,6^{\circ} \mathrm{C}$. Essa situação ocorre, pois é o momento em que o sol alcança o seu nível máximo na abóboda celeste, assim aquecendo de maneira direta a superfície terrestre, (Figura 04).

As menores temperaturas ocorreram no horário das $6 \mathrm{~h}$ e $24 \mathrm{~h}$ com médias de $27^{\circ} \mathrm{C}$ e $27,4^{\circ} \mathrm{C}$ respectivamente, no inicio da manhã e no período noturno a influência da radiação solar direta ainda não é presente por isso as temperaturas são menores, (Figura 04).

Além da influência da radiação ainda podemos citar que as características das superfícies dos materiais, são também grandes responsáveis pelas alterações nas temperaturas de superfície. Essas características são influenciadas pelas seguintes condições: período (dia ou noite), quantidade de água (seco ou úmido), cor (clara ou escura) e posição (sombreada ou exposta), (Voogt, 2004). 
Figura 05 - Temperatura do ar média nos pontos do transecto.

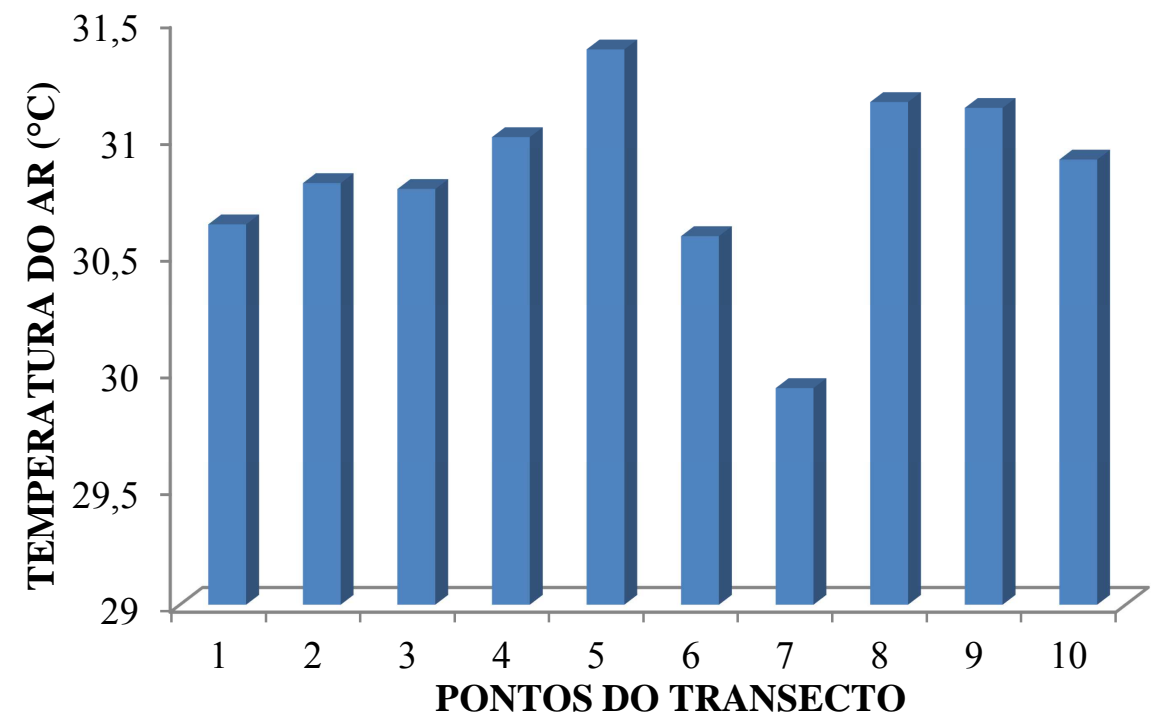

No comparativo entre as temperaturas do ar médias encontradas entre os pontos do transecto nota-se que a menor temperatura foi aferida no ponto $7 \mathrm{com}$ média de $29,9^{\circ} \mathrm{C}$, o mesmo está localizado em uma área gramada com árvores e distante da via de circulação interna do condomínio. O ponto de maior temperatura foi o $5 \mathrm{com}$ média de $31,4^{\circ} \mathrm{C}$, estando localizado em uma vaga de garagem coberta com telha de zinco, (Figura 05)

Nota-se nessa breve análise que o entorno dos pontos foi bem significativo para a diferença de temperatura do ar encontrada entre os pontos, pois apesar da pequena distância entre um ponto e outro podemos verificar um aumento de $1,5^{\circ} \mathrm{C}$.

A vegetação favorece de maneira positiva o microclima. Estudos realizados por Sailor (1995) mostram que o albedo dos materiais e o uso da vegetação influenciam diretamente o microclima urbano, chegando a reduzir as temperaturas do ar em $1,3^{\circ} \mathrm{C}$ ao aumentar em 14\% as áreas verdes na cidade de Los Angeles, Estados Unidos. 
Figura 06- Gráfico da umidade relativa do ar nos pontos do transecto.

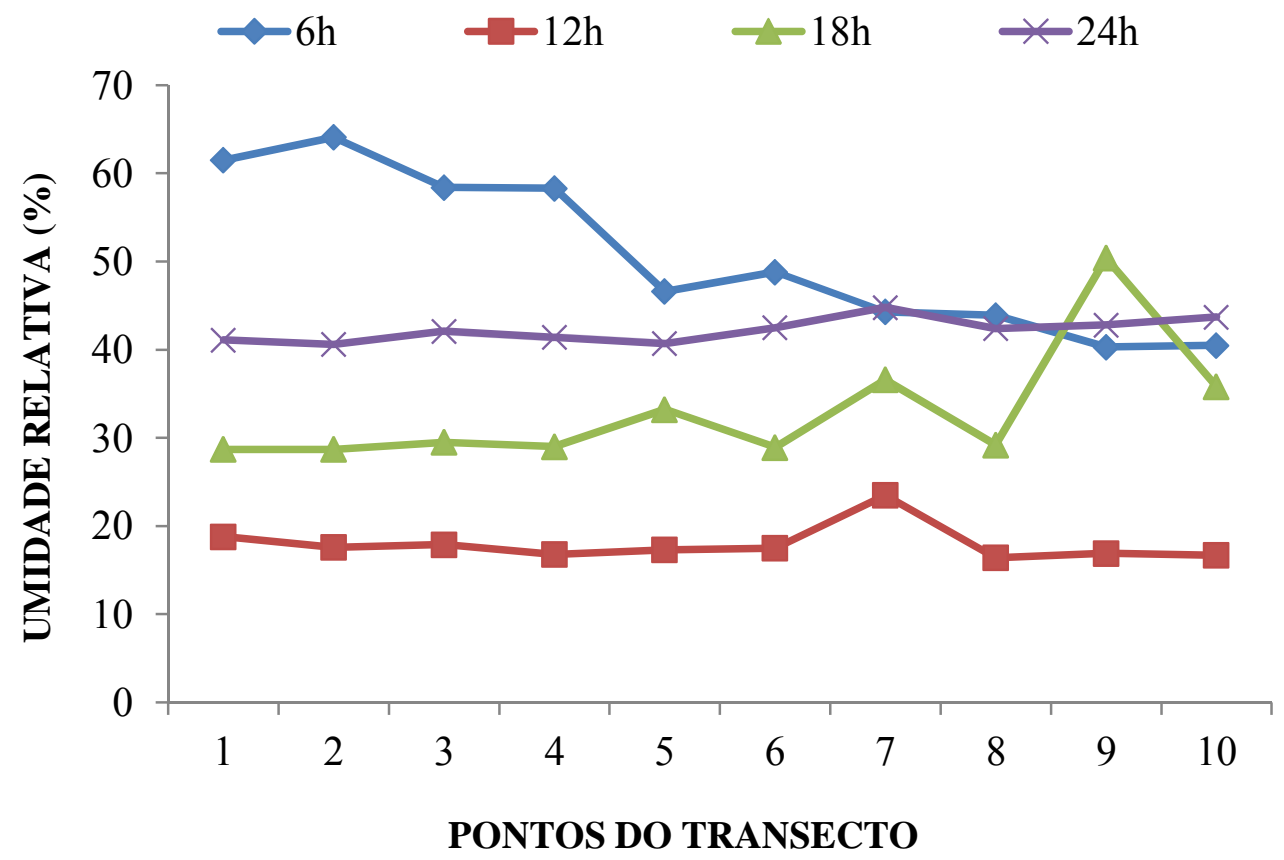

$\mathrm{Na}$ análise da umidade relativa é notado que os maiores índices de umidade ocorrem ás $6 \mathrm{~h}$ e $24 \mathrm{~h}$, com média de $50,6 \%$ e $42,2 \%$ respectivamente, isso ocorre devido a menor temperatura do ar nesse período. A menor umidade relativa foi observada ás $12 \mathrm{~h}$ com média de 17,9\%, índice preocupante, pois, segundo a Organização Mundial de Saúde (OMS), índices inferiores a 60\% não são adequados para a saúde humana, entre $12 \%$ e $20 \%$ estado de alerta, (Figura 06)

Figura 07- Umidade relativa do ar média nos pontos do transecto.

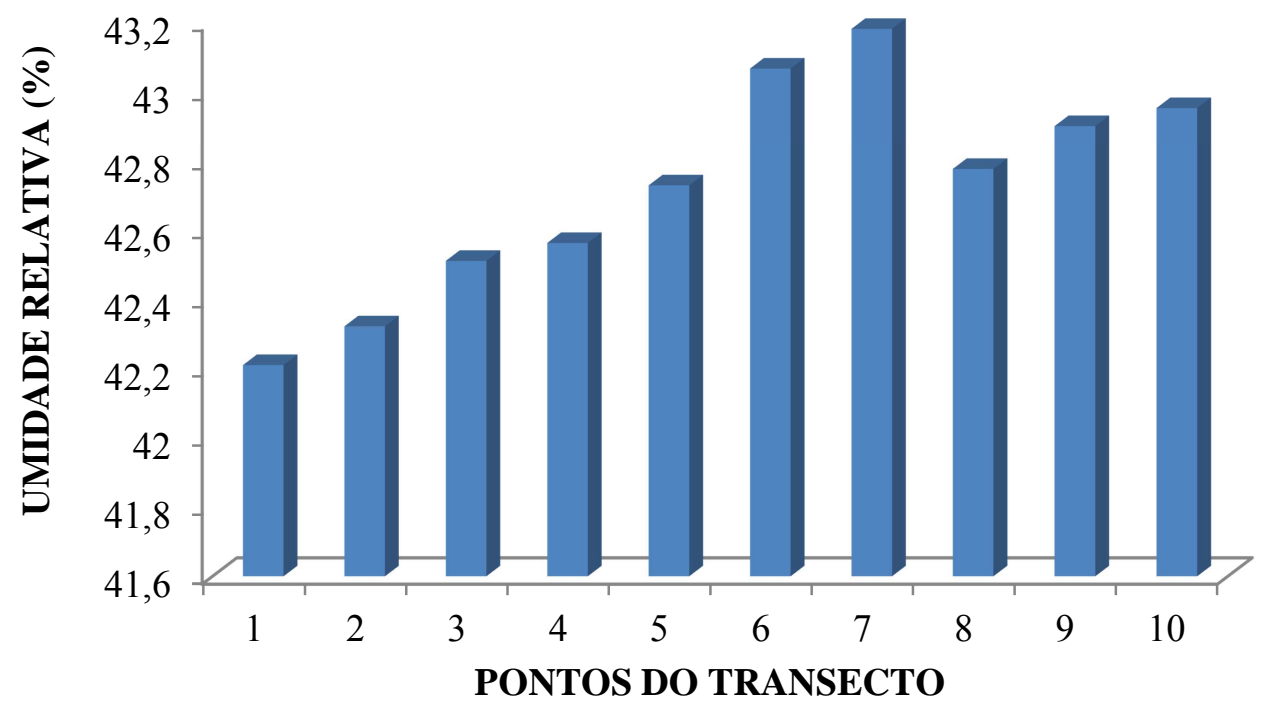


O ponto do transecto que obteve a maior umidade relativa foi o 7 com média de $43,2 \%$, consequentemente também o ponto de menor média de temperatura do ar. Esse fato deve-se a localização do ponto no condomínio, pois o mesmo encontra-se em um local gramado e bem arborizado propiciando assim um ambiente mais rico em umidade, (Figura 07).

Mascaró (1996) afirma que a umidade relativa do ar sob a vegetação é maior que nos espaços sem ela, entre 3\% a 10\%, verificando-se as maiores diferenças no verão, pois este efeito é proporcional á densidade foliar da vegetação.

O ponto de menor média de umidade relativa é o 1 com média de $42,2 \%$, esse ponto está localizado na entrada do condomínio local de alto fluxo de veículos e área construída, (Figura 07).

BRANCO et. al. 2012 ao realizarem estudos na cidade de Fortaleza, observaram que microclimas são influenciados pela presença de materiais construtivos e coberturas naturais. Quanto maior o nível de adensamento maior é a influencia dessas edificações no clima local.

\section{CONSIDERAÇÕES FINAIS}

Os resultados da análise de dados mostra que a umidade relativa do ar e a temperatura do ar variam de acordo com a configuração do ponto de coleta, apresentando que em locais com a presença de concreto, asfalto, e automóveis temperaturas mais elevadas e umidades relativas mais baixas.

No entanto as temperaturas eram mais amenas nos pontos situados mais próximos as áreas arborizadas e gramadas, onde podemos encontrar uma diferença de $1,5^{\circ} \mathrm{C}$ entre dois pontos de coleta de dados.

Sendo assim é importante salientar que há uma necessidade de se preocupar com a implantação de áreas ajardinadas em ambientes como condomínios, praças, e espaços urbanos, pensando na melhoria da qualidade ambiental desses locais.

\section{AGRADECIMENTOS}

Ao CNPq e à CAPES, pelo apoio recebido.

\section{REFERÊNCIAS}

BARROS, M. P. Dimensão fractal e ilhas de calor urbanas: uma abordagem sistêmica sobre as implicações entre a fragmentação das áreas verdes e o ambiente térmico do espaço urbano. Cuiabá, 2012. 171f. Tese (Doutorado) - Programa de Pós-Graduação em Física Ambiental, Universidade Federal de Mato Grosso.

BRANCO, K. G. C.; ZANELlA M. E.; SALES, M. C. L. O clima em áreas verdes intraurbanas de fortaleza. Revista Geonorte, Edição Especial 2, v.2, n5, p.443 - 454, 2012.

CAMPELO, JR. J. H.; CASEIRO, F. T.; FILHO, N. P.; BELLO, G. A. C.; MAITELLI, G. T.; ZANPARONI, C. A. G. P. Caracterização macroclimática de Cuiabá. In. Encontro Nacional de Estudos sobre o Meio Ambiente, Londrina, Anais. Londrina, v.1, n.7, 1991.

CAMPOS NETO, A. A. Estudo bioclimático no campus da Universidade Federal de Mato Grosso. Dissertação de Mestrado - Universidade Federal de Mato Grosso. Cuiabá - MT, 2007. 
COX, E. P. Interação entre clima e superfície Urbanizada: O caso da cidade de Várzea Grande/MT. 2008 Dissertação (Mestrado em Física e Meio Ambiente)-Departamento de Física, Universidade Federal do Mato Grosso, Cuiabá, 2008.

GAGO, E. J.; ROLDAN, J.; PACHECO-TORRES, R.; ORDÓÑEZ, J. The city and urban heat islands:A review of strategies to mitigate adverse effects. Renewable and Sustainable Energy Reviews, n²5, p. 749-758, 2013.

MASCARÓ, L. Ambiência Urbana. 1 ed. Porto Alegre: Sagra - DC Luzzatto, 1996.

REN, C.; SPIT, T.; LENZHOLZER, S.; YIM, H. L. S.; Bert HEUSINKVELD, B.; HOVE, B. V.; CHEN, L.; KUPSKI, S.; BURGHARDT, R.; KATZSCHNER, L. Urban Climate Map System for Dutch spatial planning. International Journal of Applied Earth Observation and Geoinformation, ${ }^{\circ}$ 18, p. 207-221, 2012.

SAILOR, D. J. Simulated urban climate response to modifications in surface albedo and vegetative cover. Journal of Applied Meteorology, v.34, 1995.

SHASHUA-BAR L.; PEARLMUTTER D.; ERELL E. The cooling efficiency of urban landscape strategies in a hot dry climate. Landscape and Urban Planning, $n^{\circ} 92$, p. 179-186, 2009.

SHASHUA-BAR L., TSIROS I. X., HOFFMAN M. Passive cooling design options to ameliorate thermal comfort in urban streets of a Mediterranean climate (Athens) under hot summer conditions. Building and Environment 2012; 57: 110 e 119.

SOUCH, C.; GRIMMOND, S. Applied climatology: urban climate. Progress in Physical Geography, n³0, p. 270-27, 2006.

WIRDOYO, J. (2008). Vegetation Configuration as Microclimate Control Strategy in Hot Humid Tropic urban Open Space. International Symposium \& Exhibition In Sustainable Energy \& Environment. S E N V A R + I S E S E E 1-3 December 2008.

VOOGT, J. A. Urban heart islands: hotter cities. 2004. 